\title{
Traumatic Basilar Artery Occlusion Caused by a Fracture of the Clivus
}

\author{
-Case Report-
}

\author{
Sumito SATO, Hideo IIDA**, Hisashi Hirayama, Masataka ENDO, \\ Takashi OHWADA*, and Kiyotaka FUJII
}

\begin{abstract}
Departments of Neurosurgery and ${ }^{*}$ Critical Care and Emergency Medicine, Kitasato University School of Medicine, Sagamihara, Kanagawa; ${ }^{* *}$ Department of Neurosurgery, International Goodwill Hospital, Yokohama, Kanagawa
\end{abstract}

\begin{abstract}
A 56-year-old man presented with a rare traumatic basilar artery occlusion caused by a fracture of the clivus. He fell from the height of 2 meters and immediately fell into a coma. Head computed tomography (CT) revealed an open depressed fracture, an acute epidural hematoma $1 \mathrm{~cm}$ thick in the left middle frontal fossa, and a longitudinal fracture of the clivus. Emergency removal of the hematoma was performed with cranioplasty. Head CT 8 hours 50 minutes after injury showed infarctions in the brain stem, cerebellum, and occipital lobes. Cerebral angiography revealed occlusion of the basilar artery in the middle part of the clivus. The patient died after 3 days. Autopsy revealed that the basilar artery was trapped in the clivus fracture site. Vertebrobasilar artery occlusion due to trapping in a clivus fracture has a very poor prognosis. Diagnosis is difficult and generally only confirmed at autopsy. Cerebral angiography is recommended in a patient in a deep coma without massive brain contusion at the early stage of head injury to identify the possibility of vertebrobasilar artery occlusion in a clivus fracture.
\end{abstract}

Key words: clivus fracture, basilar artery occlusion

\section{Introduction}

Clivus longitudinal fracture caused by trauma and associated with trapping and occlusion of the basilar artery within the fracture is very rare, with only six cases reported. ${ }^{1,3,6-10)}$ The present report concerns our own findings for one case and comparison with the literature.

\section{Case Report}

A 56-year-old man fell from a height of approximately 2 meters onto a concrete surface at around 2 p.m. on November 7, 1997. An emergency medical team arrived about 15 minutes later. His consciousness was deep coma (Japan Coma Scale [JCS] 300). His pupils had dilated to $6 \mathrm{~mm}$ diameter and the light reflex was lost. He was intubated at a nearby medical facility and arrived at our hospital at 3:15 p.m.
On admission his blood pressure was $110 \mathrm{mmHg}$, and his pulse was 110 beats per minute, with an essentially normal respiration rate of 28 . The left side of the cranium demonstrated an open depressed fracture with nasal but no aural bleeding. Neurological examination found he was in a deep coma (JCS 200), Glasgow Coma Scale E(1)V(1)M(3), with pupillary diameter of $2 \mathrm{~mm}$ and loss of the light reflex on both sides. A left frontal bone to temporal bone fracture was evident with a depressed fracture on the left parietal bone (Fig. 1). Head computed tomography (CT) showed a left acute epidural hematoma, traumatic subarachnoid hemorrhage around the brain stem, intraventricular hemorrhage, hemorrhage of the sphenoid and ethmoidal sinuses, pneumocranium, longitudinal fracture of the clivus, and an open depressed fracture of the parietal bone (Figs. 2 and 3).

Shortly after admission the patient suffered a

Received June 8, 2001; Accepted August 29, 2001

Author's present address: S. Sato, M.D., Department of Neurosurgery, International Goodwill Hospital, Yokohama, Kanagawa, Japan. 


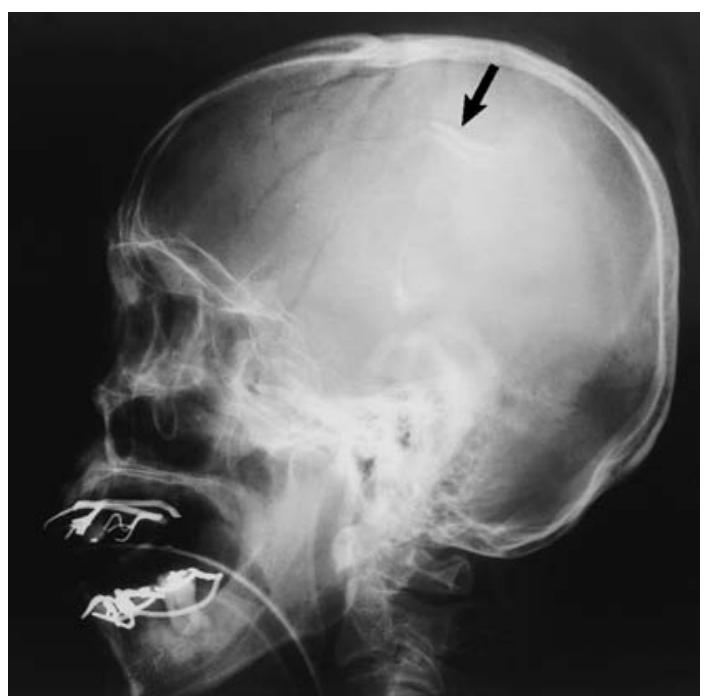

Fig. 1 Head radiograph taken on admission showing a $5 \mathrm{~cm}$ longitudinal fracture (arrow) in the area of the depressed fracture.
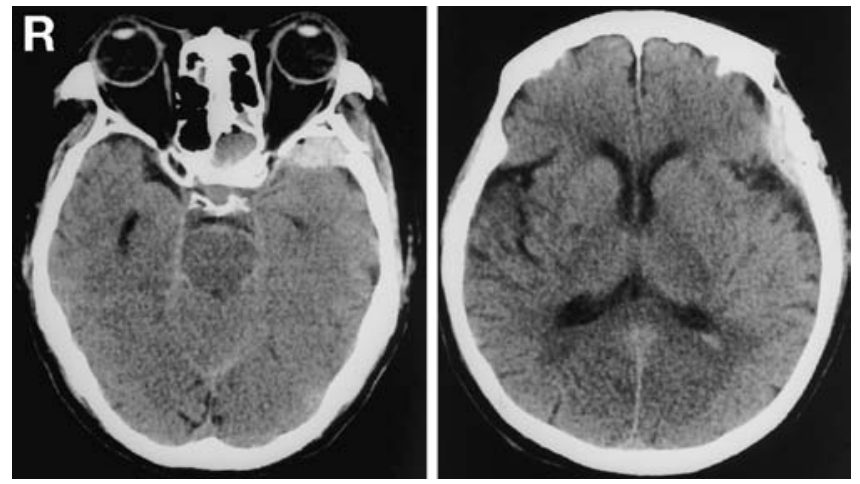

Fig. 2 Head computed tomography scans on admission showing (left) an acute epidural hematoma in the left middle cranial fossa, and (right) traumatic intraventricular hemorrhage and subarachnoid hemorrhage.

generalized convulsion. An intracranial pressure (ICP) sensor was installed and measured a value of 8 $\mathrm{mmHg}$. Imaging studies revealed acute subdural hematoma but diffuse brain injury was considered to be the cause of the immediate onset of consciousness disturbance. The ICP was normal, but an open cranial fracture was present, so an emergency open cranial operation was performed to resect the hematoma with cranioplasty starting at $4: 45$ p.m. The patient did not recover consciousness after the surgery.

CT revealed massive low density areas in the brain stem, cerebellar hemisphere and bilateral occipital lobes at 10:50 p.m. (Fig. 4). Occlusion of the basilar

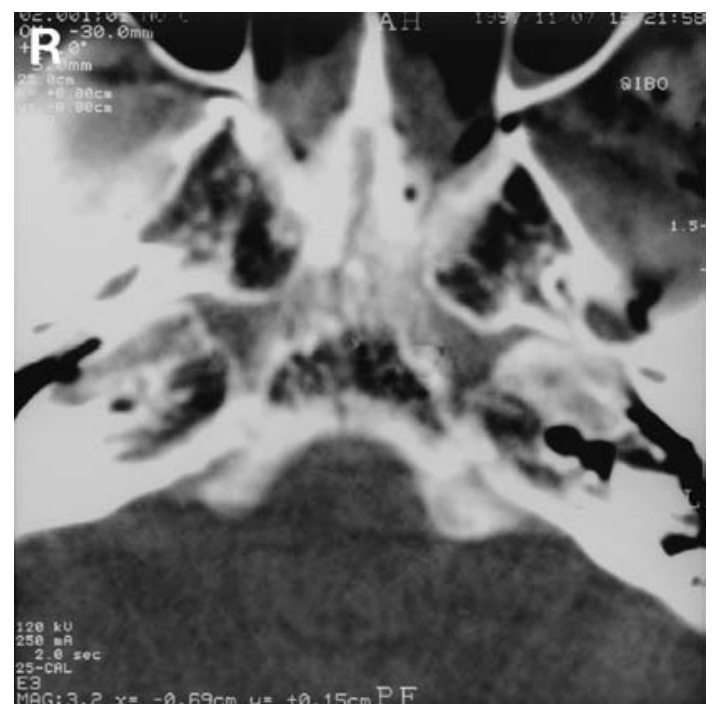

Fig. 3 Bone window computed tomography scan on admission showing a longitudinal fracture.

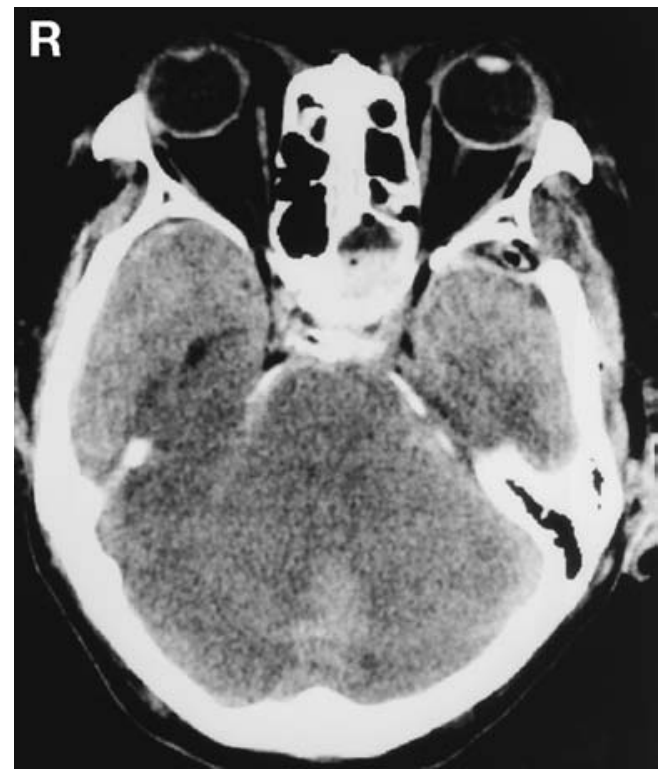

Fig. 4 Computed tomography scan taken 7.5 hours after admission showing low density areas in the brain stem, cerebellar hemispheres, and occipital lobes.

artery was highly suspected. Immediate vertebral angiography showed occlusion of the basilar artery at the level of the middle clivus (Fig. 5). Carotid angiography demonstrated no apparent communication from the posterior communicating artery to the vertebrobasilar arteries. The patient exhibited general deterioration and died on November 10.

Autopsy identified a longitudinal clivus fracture 


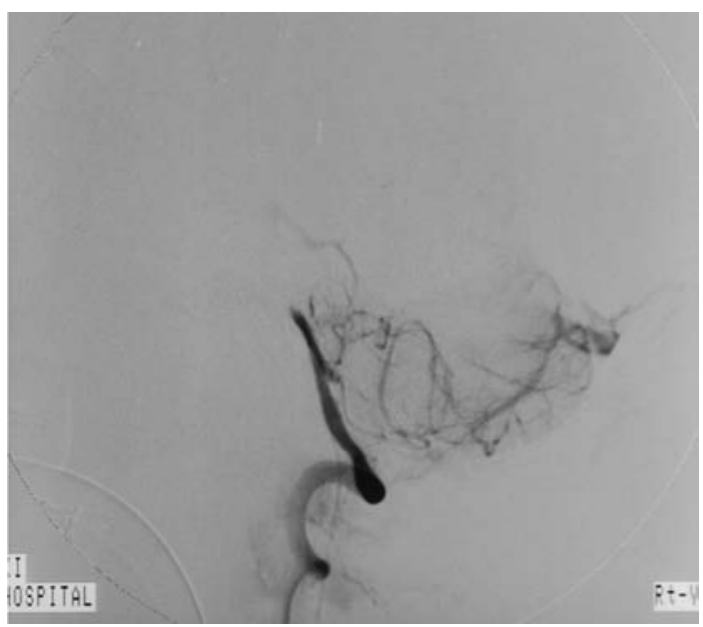

Fig. 5 Right vertebral angiogram showing occlusion of the basilar artery with the vertebral artery filled as far as the posterior inferior cerebellar artery.

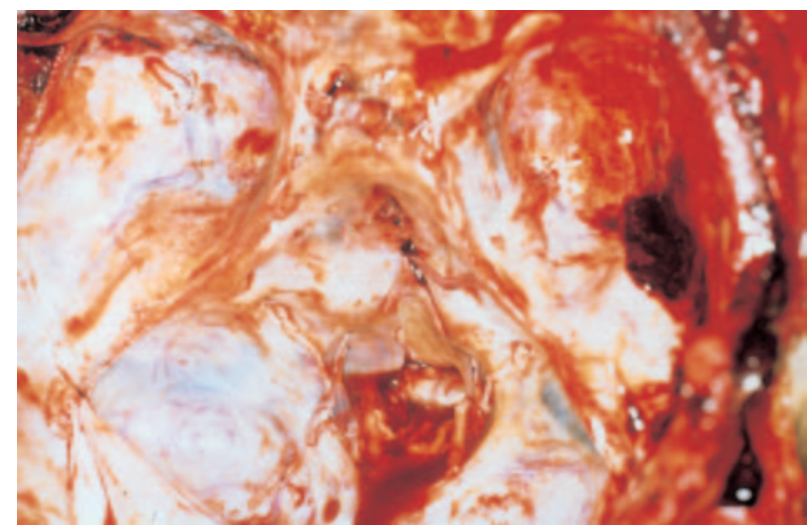

Fig. 6 Autopsy photograph showing the longitudinal dural laceration and fracture of the clivus, and trapping of the basilar artery.

which had trapped a 1-cm length of the basilar artery (Fig. 6). Histological examination showed the lumen of the basilar artery was occluded and the internal elastic layer was torn in the fracture line (Fig. 7).

\section{Discussion}

Head radiography cannot easily demonstrate fracture of the clivus, but current bone window CT imaging has clearly shown that this condition is not as infrequent as previously thought. CT of a large series of 3000 patients admitted for head trauma over a period of 30 months found that $17(0.57 \%)$ had clivus fractures. Clivus fractures can be classified into three types: longitudinal, transverse, and oblique,

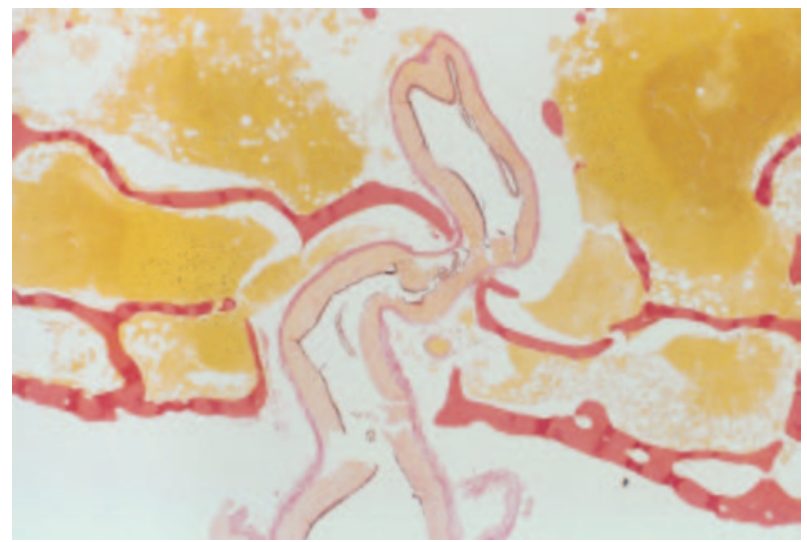

Fig. 7 Photomicrograph illustrating the trapped basilar artery in the fracture line with occlusion of the lumen and loss of the integrity of the inner elastic layer. Elastica-van Gieson stain, $\times 5$.

and were most often associated with trauma caused by traffic accidents and falls. The longitudinal type frequently causes death because the vertebral and basilar arteries are trapped in the fracture line and occlusion occurs with subsequent unusual complications. The transverse type occurs as a diastatic fracture of the spheno-occipital synchondrosis, and together with the oblique type is often accompanied by multiple cranial nerve paresis, Horner's syndrome, carotid-cavernous sinus fistula, stenosis in the carotid canal, and cerebrospinal fluid otorrhea. ${ }^{2,4,5)}$

Previously, only six cases of occlusion of the vertebrobasilar arteries by longitudinal fracture of the clivus have been reported (Table 1)..$^{1,3,6-8,10)}$ The diagnosis was confirmed at autopsy in five cases, and based on CT and cerebral angiography findings in one case. The mechanism of the trapping of the artery in the fracture was considered in several cases as follows. A traffic vehicle accident caused a brain contusion immediately below the right frontal area of direct injury and a linear fracture occurred, with the sudden deformation of the cranium causing instantaneous bursting of the clivus resulting in a longitudinal fracture and laceration of the dura mater. ${ }^{10)}$ The inertial forward movement of the brain stem and cerebellum pressed the basilar artery into the fracture gap, and subsequently the fracture gap closed on the artery. ${ }^{10)}$ Falling objects impacting on the forehead caused compression and impaction of the cranial base between the vertebral bodies of the spine so that the clivus was laterally lacerated trapping the basilar artery. Restoration of the deformed cranium closed the fracture and trapped the 
Table 1 Summary of reported cases of vertebrobasilar artery trapping in a longitudinal clivus fracture

\begin{tabular}{|c|c|c|c|c|c|c|}
\hline Author (Year) & $\begin{array}{l}\text { Age/ } \\
\text { Sex }\end{array}$ & $\begin{array}{l}\text { Mechanism of } \\
\text { injury }\end{array}$ & $\begin{array}{l}\text { Consciousness level } \\
\text { at admission }\end{array}$ & Trapped artery & $\begin{array}{l}\text { Other intracranial } \\
\text { lesions; ICP }\end{array}$ & Cause of death \\
\hline $\begin{array}{l}\text { Loop et al. } \\
\left.(1964)^{7}\right)\end{array}$ & $59 / \mathrm{M}$ & $\begin{array}{l}\text { hit by a falling } \\
\text { beam }\end{array}$ & $\begin{array}{l}\text { unconscious, } 30 \text { min after } \\
\text { the accident }\end{array}$ & basilar & thin EDH; ND & $\begin{array}{l}\text { brain stem } \\
\text { infarction }\end{array}$ \\
\hline $\begin{array}{l}\text { Lindenberg } \\
(1966)^{6)}\end{array}$ & $42 / \mathrm{M}$ & fall & $\begin{array}{l}\text { orientated, } 45 \text { min after } \\
\text { the accident }\end{array}$ & lt vertebral & $\begin{array}{l}\text { thin SDH, some SAH, small } \\
\text { cortical contusion; ND }\end{array}$ & $\begin{array}{l}\text { aspiration } \\
\text { pneumonia }\end{array}$ \\
\hline Sights $(1968)^{10)}$ & $23 / \mathrm{M}$ & $\begin{array}{l}\text { automobile } \\
\text { accident }\end{array}$ & $\begin{array}{l}\text { deep coma, } 2 \text { hrs after } \\
\text { the accident }\end{array}$ & basilar & local cerebral contusion; ND & $\begin{array}{l}\text { brain stem } \\
\text { infarction }\end{array}$ \\
\hline $\begin{array}{l}\text { Anthony et al. } \\
(1987)^{1)}\end{array}$ & $70 / \mathrm{M}$ & fall & unconscious & basilar & none; ND & $\begin{array}{l}\text { brain stem } \\
\text { infarction }\end{array}$ \\
\hline $\begin{array}{l}\text { Guha et al. } \\
(1989)^{3)}\end{array}$ & $27 / \mathrm{M}$ & fall & unconscious, immediately & basilar & none; 15 mmHg & (vegetative) \\
\hline $\begin{array}{l}\text { Sato et al. } \\
(1990)^{8)}\end{array}$ & $80 / \mathrm{M}$ & $\begin{array}{c}\text { automobile } \\
\text { accident }\end{array}$ & $\mathrm{E}(1) \mathrm{V}(1) \mathrm{M}(3)$, immediately & $\begin{array}{l}\text { basilar and } \\
\text { rt vertebral }\end{array}$ & IVH, SAH; ND & $\begin{array}{l}\text { brain stem } \\
\text { injury }\end{array}$ \\
\hline Present case & $56 / \mathrm{M}$ & fall & $\begin{array}{l}\mathrm{E}(1) \mathrm{V}(1) \mathrm{M}(3), 1 \mathrm{hr} \text { after } \\
\text { the accident }\end{array}$ & basilar & EDH, SAH, IVH; 8 mmHg & $\begin{array}{l}\text { brain stem } \\
\text { infarction }\end{array}$ \\
\hline
\end{tabular}

EDH: epidural hematoma, ICP: intracranial pressure, IVH: intraventricular hemorrhage, ND: not described, SAH: subarachnoid hemorrhage, SDH: subdural hematoma.

artery. ${ }^{7,9)} \mathrm{A}$ perpendicular falling force transmitted pressure to the clivus via the vertebral body. ${ }^{1)} \mathrm{A}$ blow caused a midline occipital fracture with force transmission via the foramen magnum. ${ }^{8)}$ The brain stem was jolted forward and the basilar artery temporarily entered the enlarged fracture line and became trapped. ${ }^{8)}$ In the present case, the initial direct blow to the right parietal area, caused by the fall, probably resulted in the depressed fracture, with subsequent pressure on the head through the vertebra as the body made contact with the ground acting as a reactive force, as with previous cases. ${ }^{1,7,9)}$

Most patients have arrived at hospital in a coma which began shortly after the injury. Two cases had no intracranial space-occupying lesion by CT which could account for the loss of consciousness. Bone window CT images revealed longitudinal fractures of the clivus in both cases, and one was confirmed at autopsy. The consciousness level on admission was also coma and CT also showed acute epidural hematoma and traumatic subarachnoidal hemorrhage with ICP within the normal range. The serious consciousness disturbance could not be explained by any intracranial space-occupying lesion. In our case, follow-up CT demonstrated low- density areas of the brain stem and cerebellum, and cerebral angiography revealed the arterial occlusion. Cerebral angiography was performed in only two previous patients to identify this condition.

Longitudinal fracture of the clivus causing traumatic basilar artery occlusion is very rare, and carries a very poor prognosis. Definitive diagnosis is difficult before death. We recommend that angiography should be performed to identify vertebrobasilar arterial occlusion in patients admitted in a coma after head trauma if CT shows no space- occupying lesion.

\section{References}

1) Anthony DC, Atwater SK, Rozear MP, Burger PC: Occlusion of the basilar artery within a fracture of the clivus. J Neurosurg 66: 929-931, 1987

2) Corradino G, Wolf AL, Mirvis S, Joslyn J: Fractures of the clivus: classification and clinical features. Neurosurgery 27: 592-596, 1990

3) Guha A, Fazl M, Cooper PW: Isolated basilar artery occlusion associated with a clivus fracture. Can J Neurol Sci 16: 81-83, 1989

4) Joslyn JN, Mirvis SE, Markowitz B: Complex fractures of the clivus: Diagnosis with CT and clinical outcome in 11 patients. Radiology 166: 817-821, 1988

5) Kapila A, Chakeres DW: Clivus fracture: CT demonstration. J Comput Assist Tomogr 9: 1142-1144, 1985

6) Lindenberg R: Incarceration of a vertebral artery in the cleft of a longitudinal fracture of the skull. J Neurosurg 24: 908-910, 1966

7) Loop JW, White LE, Shaw CM: Traumatic occlusion of the basilar artery within a clivus fracture. Radiology 83: 36-40, 1964

8) Sato H, Sakai T, Uemura K: [A case of incarceration of the vertebral and basilar arteries in a longitudinal fracture of the clivus]. No Shinkei Geka 18: 1147-1150, 1990 (Jpn, with Eng abstract)

9) Shaw CM, Ellsworth CA: Injury of the basilar artery associated with closed head trauma. J Neurol Neurosurg Psychiatry 35: 247-257, 1972

10) Sights WP: Incarceration of the basilar artery in a fracture of the clivus. J Neurosurg 28: 588-591, 1968

Address reprint requests to: S. Sato, M.D., Department of Neurosurgery, International Goodwill Hospital, 1-28-1 Nishigaoka, Izumi-ku, Yokohama, Kanagawa 245-0006, Japan. 